\title{
THE EFFECT OF PROLONGED ADMINISTRATION OF SULFANILA- MIDE ON RATS WITH NEPHROTOXIC NEPHRITIS
}

\author{
By JOSEPH E. SMADEL AND HOMER F. SWIFT \\ (From the Hospital of The Rockefeller Institute for Medical Research, New York City)
}

(Received for publication July 28, 1939)

Treatment with sulfanilamide is sometimes indicated in patients suffering from nephritis or in those with infections which may lead to renal disease; hence, it is desirable to know whether a damaged kidney has an increased susceptibility to this drug. Several investigators $(1,2)$ have reported that administration of sulfanilamide to normal rats over long periods, in daily amounts somewhat greater than those used for man, is not associated with the development of renal lesions, but there is not complete agreement on this point (3). For a general discussion of the toxic effects of sulfanilamide the recent review of Marshall (4) may be consulted.

The present work was undertaken to determine whether rats with experimental glomerulonephritis will tolerate sulfanilamide ${ }^{1}$ when given in doses comparable to those usually employed for human beings. Since it is possible to alter significantly the course of nephrotoxic nephritis in rats by feeding different diets (5), it was proposed to employ this procedure to influence the renal changes toward regression or progression in rats with induced nephritis. Thus, animals with different degrees of renal disease would be available for testing the effect of sulfanilamide in the injured kidney.

An unexpected factor, i.e., heredity, entered into the experiment and necessitated a redivision of the original groups of rats for an adequate interpretation of results; consequently, the number of animals in each of the final groups was small. Nevertheless, the uniform response of the rats to the drug justifies a report of the observations.

\section{EXPERIMENTAL METHODS}

Anti-kidney serum-This serum was prepared in rabbits by the intraperitoneal injection of suspensions of

1 The sulfanilamide used was the brand known as Prontylin, kindly supplied by the Winthrop Chemical Company, Inc. perfused kidney tissue obtained from rats of the Whelan strain. Anti-serum number 4557, used in preceding experiments (5), was injected intravenously into rats in a dosage of $0.75 \mathrm{cc}$. per 100 grams of body weight. This total amount was given in three divided doses on consecutive days. Most of the animals received an additional $0.25 \mathrm{cc}$. of anti-kidney serum five weeks after the original injection.

Strains of rats-Only a few hooded rats of the socalled Whelan strain which we had used throughout our earlier work were available when the present investigation was undertaken. As a result, two members of this inbred line, of opposite sexes, were placed in each of six groups; and in addition twenty hooded rats of the Evans strain were used to complete the requisite number. Animals weighing 50 to 60 grams when received were observed for a week and subjected to repeated urine analyses. The animals received the initial injection of nephrotoxin when they weighed about 75 grams.

Care of animals-Rats were kept in separate jars and fed one of two purified diets. The constituents in these rations have been described elsewhere (5), and it is sufficient to say here that only the protein and carbohydrate contents were varied. The high protein diet contained 40 per cent lactalbumen and 29 per cent of a mixture of Karo powder and cane sugar; the low protein diet contained 5 per cent protein and 64 per cent carbohydrate.

Urine analyses and determination of body weight were made on alternate days for the first six weeks and once or twice weekly thereafter.

Rats were sacrificed three months after nephritis had been induced and complete autopsies were performed. Sections for microscopic study were always prepared from kidney and heart and usually from the pancreas and brain. Paraffin sections of kidney tissue were stained by the usual methods and, in addition, by Mallory's aniline blue stain and McGregor's modification (6) of the Mallory Heidenhain technique.

Administration of sulfanilamide and estimation of its excretion-Sulfanilamide was usually given by mouth, but when quantitative estimations of urinary excretion were made the drug was injected subcutaneously. Stock solutions for use by either route were prepared by dissolving the drug in boiling Ringer's Solution and, after cooling, adding sufficient sterile diluent to bring the concentration of sulfanilamide to $5 \mathrm{mgm}$. per cc. For oral administration a proper amount of the stock solution of drug, i.e., $1.0 \mathrm{cc}$. per 100 grams of body weight, was placed in the individual drinking bottle of each rat and $3.0 \mathrm{cc}$. of a 10 per cent solution of Karo syrup in water 
were added. Animals took this mixture avidly and rarely wasted more than a few drops.

The method of determining the urinary excretion of sulfanilamide was similar to that employed by Marshall and Cutting (7) and was carried out as follows: On Monday morning a sample of urine was collected and examined in order to be certain that the last dose of the drug, given on Friday, was no longer being excreted in appreciable amounts. Late that afternoon each rat was injected subcutaneously with a proper amount of the stock solution of sulfanilamide, placed in a metabolism jar for collection of urine, and given a drinking bottle containing $15 \mathrm{cc}$. of diluted Karo to insure an adequate volume of urine. The next morning, sixteen and onehalf hours after injection, the residual urine was pressed from the rat's bladder and the total volume was measured. An aliquot portion of the sample of urine was used to determine the concentration of sulfanilamide. The urinary excretion of the drug was expressed as the percentage of the injected amount which was excreted in both the free and combined form over a period of sixteen and one-half hours. Estimations of free and combined sulfanilamide were made on urine and blood by the techniques of Marshall (8).

Grouping of experimental animals-Severe glomerulonephritis was induced in twenty-four young rats by means of anti-kidney serum. Half of the animals were then placed on a low protein diet while the remainder were given a high protein diet. Six of the nephritic animals in each diet group received sulfanilamide in doses of 0.05 gram per kilo of body weight on five consecutive days each week for a period of ten weeks; the other rats with nephritis were kept as controls. Eight additional control animals which did not receive nephrotoxin were treated with sulfanilamide; these also were distributed in equal groups and given one of the two diets. Each of the six groups of animals consisted of two rats of the Whelan strain and two or four of the Evans strain.

\section{RESULTS}

Differences in the response of Whelan and Evans rats to nephrotoxin. A striking difference in the course of the nephritis in the two strains of rats was apparent by the end of the first month. Animals of the Whelan strain behaved as in previous experiments (5), i.e., the nephritis rapidly subsided and became of mild intensity in the rats fed the low protein diet, while in the high protein diet group the nephritis continued to be severe. On the other hand, the acute nephritis induced in the Evans strain of rats by nephrotoxin rapidly subsided irrespective of the diet fed. These findings are clearly shown in Figures 1 and 2 , in which graphic representations are presented of the average urinary albumen and casts excreted by the members of the different groups.
Since the nephritis subsided in most of the animals more rapidly than we had originally anticipated, all rats, except those of the Whelan strain maintained on a high protein diet, were given a second series of injections of nephrotoxin; this second dosage consisted of one-third of the amount of the first dose and was given five weeks after the initial injection. In order to avoid fatal anaphylactic reactions, the animals were first desensitized by injecting $0.05 \mathrm{cc}$. of anti-kidney serum; on the following day the remainder of the nephrotoxin was given. This procedure was apparently successful with the Whelan strain of rats since neither injection was followed by any anaphylactic reaction. The Evans strain of rats, however, almost invariably developed signs of a slight or moderate reaction after each injection. These observations, which apparently indicate that the former strain was less sensitive to rabbit serum than the latter, suggest an explanation for the different renal response of the two rat strains to reinjection. For example, circulating antibody in rats sensitive to rabbit serum might combine with the rabbit nephrotoxin and thus prevent its acting on the kidney. The second course of nephrotoxin was followed by a moderate exacerbation of nephritis in the animals of the Whelan strain and a slight recurrence in members of the Evans strain of rats fed the high protein diet; however, no appreciable increase of renal irritation was observed in reinjected rats of the Evans strain which were being fed the low protein diet.

Additional observations on the various responses of different inbred strains of rats to nephrotoxin will be reported in the near future. It may be mentioned here, however, that the histological evidence for recovery from renal injury observed in rats of the Evans strain fed the high protein diet is similar in many respects to that previously noted in animals of the Whelan line maintained on a low protein diet (5).

Administration of sulfanilamide to normal and nephritic rats. The administration of sulfanilamide in the manner described above to nephritic rats had no obvious effect on the course of the renal disease. In every instance the degree of urinary abnormality and the rate of growth were practically identical for rats of the same strain in a given diet group, whether sulfanilamide was ingested or not. Furthermore, no apparent dif- 
MHTAM STRATH RATS
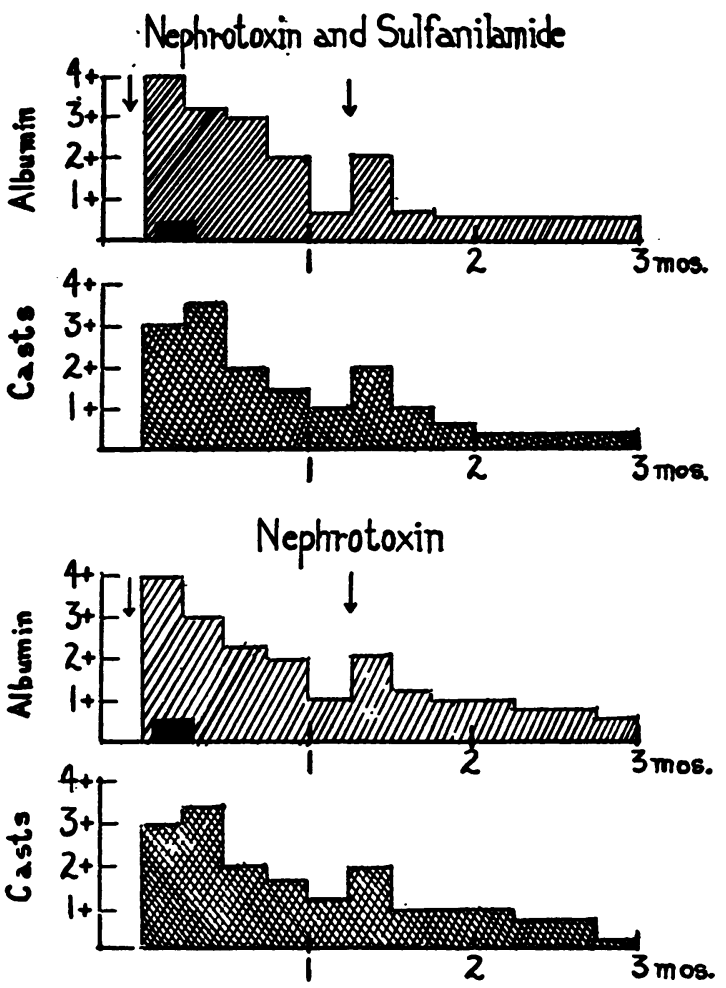

ENANS gTRATI RaTs
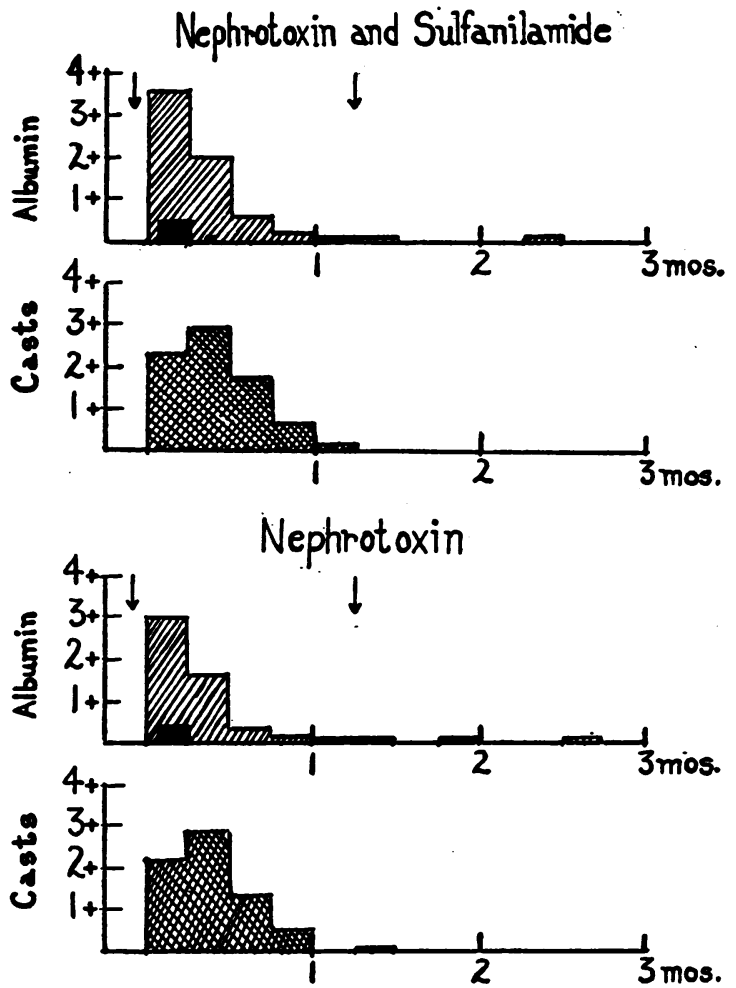

Fig. 1. Effect of Sulfanilamide on Course of Nephrotoxic Nephritis in Rats Maintained on a Low Protein Diet

Arrows indicate injection of nephrotoxin. Initial amount of anti-kidney serum was 0.75 cc. per 100 grams of body weight; the second dose was $0.25 \mathrm{cc}$. per 100 grams of body weight. The presence of edema is represented by the solid black areas.

ferences were noted on pathological examination. The graphs in Figures 1 and 2 summarize the urinary findings in the nephritic animals which received the drug in each diet and strain group, as well as in the controls receiving no drug.

A second set of control rats which did not receive nephrotoxin excreted normal urine throughout the period while they received sulfanilamide. Moreover, no changes were observed in their kidneys on microscopic examination except those which have been recorded in normal animals maintained on these two diets (5).

There was no significant difference in the excretion of sulfanilamide by normal and nephritic rats fed the low protein diet. The average values for the entire period were 70 per cent in the former group and 73 per cent in the latter. The results obtained in the high protein diet group were more variable and may indicate a diminution in excretion of the drug by animals with induced renal injury during the second week after injection. Nevertheless, the average excretion values in these groups of normal and nephritic animals were not greatly different, being 81 per cent and 70 per cent, respectively. The amount of free drug in the urine, determined before hydrolysis, was in general about 35 per cent of the total sulfanilamide excreted. The results of observations on the urinary excretion of sulfanilamide are summarized in Figure 3.

Retention of sulfanilamide, which may occur in patients with severe nephritis (9), was not noted in our animals; however, none of the rats developed renal failure during the relatively short course of the experiment. Urine collected before each excretion test, i.e., approximately sixty hours after the last administration of the drug, contained very small amounts of sulfanilamide; only 
WHELAN STRAIN RATS
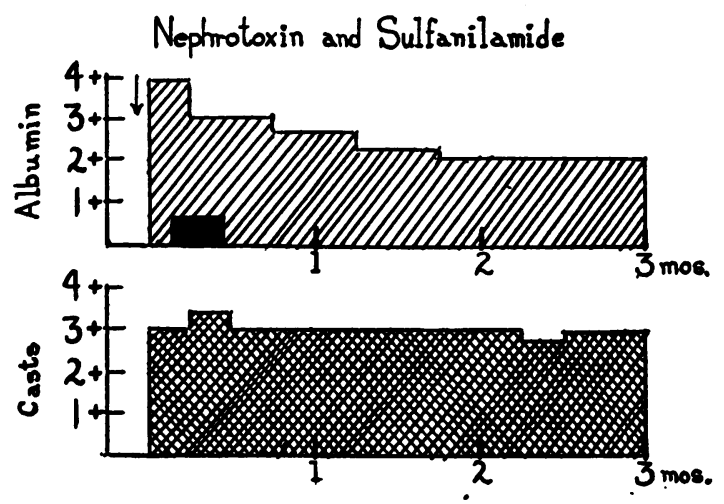

Nephrotoxin
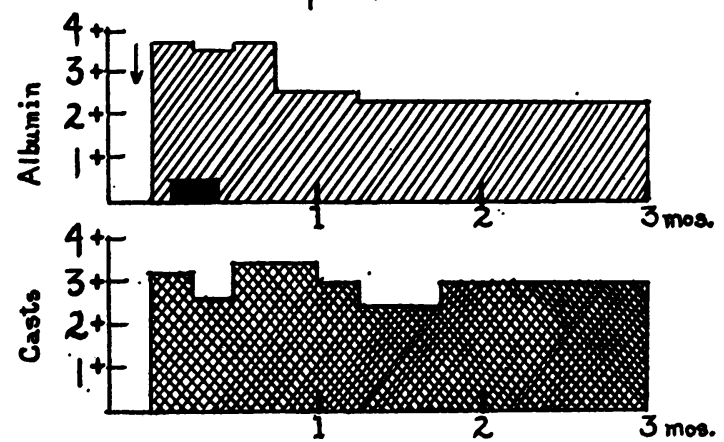

EVANS STRAIY RATS

Nephrotoxin and Sulfanilamide.
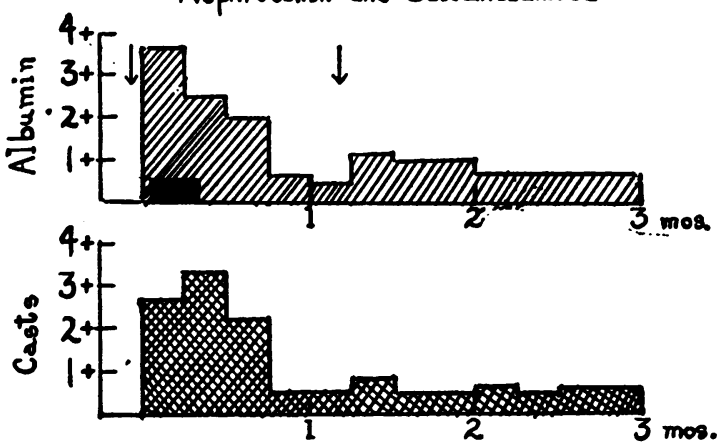

Nephrotoxin

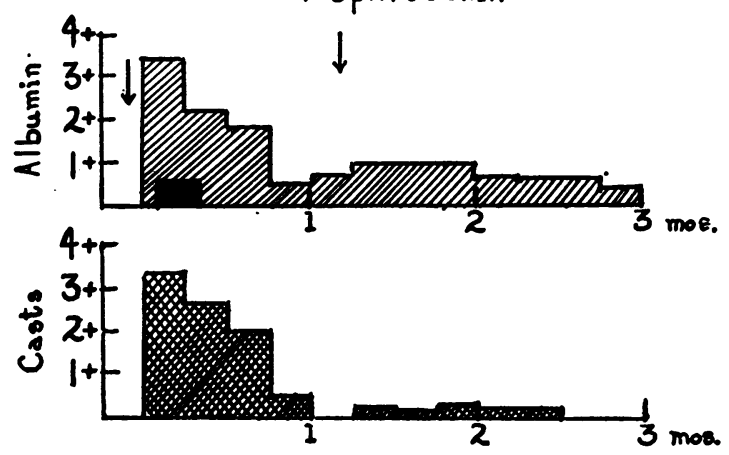

Fig. 2. Effect of Sulfanilamide on Course of Nephrotoxic Nephritis in Rats Maintained on a High Protein Diet

Arrows indicate injection of nephrotoxin. Initial amount of anti-kidney serum was $0.75 \mathrm{cc}$. per 100 grams of body weight. Evans rats received a second dose of 0.25 cc. per 100 grams of body weight. The presence of edema is represented by the solid black areas.

on a few occasions was a concentration of 0.01 mgm. per cent recorded. Furthermore, at the end of the experiment, each rat was injected subcutaneously with an amount of drug equal to 15 mgm. per 100 grams of body weight and bled from the heart sixteen hours later. No notable variation in the amount of drug was detected in the blood of nephritic and control animals of a given diet group, but a considerable difference in the blood level was observed in rats fed the high and low protein diets. Thus, the values 3.4 and $2.6 \mathrm{mgm}$. per cent represented the average blood level of sulfanilamide in the nephritic and control rats fed the high protein diet, while 10.9 and 10.5 $\mathrm{mgm}$. per cent were the average values for the two groups of animals fed the low protein diet. An explanation of this difference is not at hand. However, the excretion of larger volumes of urine by rats on the high protein diet may have been a factor in reducing the blood level of the drug in this group. The results on the whole are similar to those obtained by Marshall and Cutting in their studies on excretion of sulfanilamide by normal rats (7).

\section{DISCUSSION}

The present experiments indicate that rat kidneys, which have been subjected to various degrees of damage by a combination of nephrotoxic serum and injurious or beneficial diets, are not appreciably affected by sulfanilamide given over relatively long periods in daily dosage of approximately 0.05 gram per kilo of body weight, the usual maximal dosage for man. These observations, moreover, are in accord with those of the majority of workers who could find no significant changes in the kidneys after administering this 
LON PBOTEIN DIET GROUP

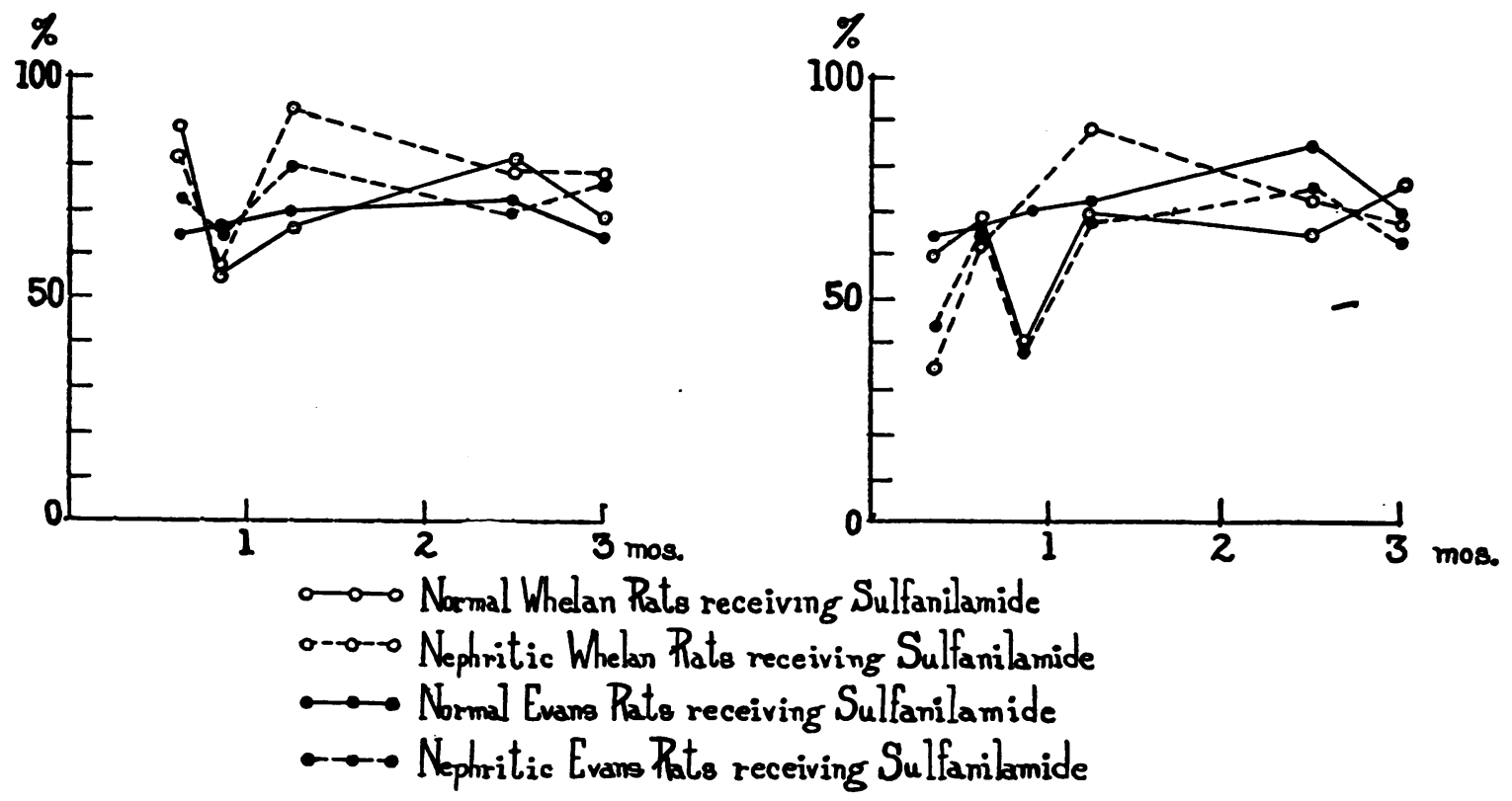

Fig. 3. Urinary Excretion of Sulfanilamide by Normal and Nephritic Rats Maintained on DifFerent Diets

Nephritis was induced March 26, 1937. Sulfanilamide, begun ten days later, was given on five consecutive days each week in doses of 0.05 gram per kilo of body weight. Per cent excretion of sulfanilamide represents the proportion of drug, free and combined, in the urine secreted during sixteen and one-half hours after administration.

drug to normal rats for considerable periods. The inference is clear, therefore, that neither normal nor diseased renal tissue of rats is detectably injured by the necessity for excreting sulfanilamide in moderate amounts. This is in contrast to the recently recorded observations made on rats treated with sulfapyridine $(10,11)$ which inflicted definite renal damage.

The ability of the nephrotoxin-injured rats' kidneys to excrete sulfanilamide at a normal rate may be contrasted with the lowered capacity of human nephritic kidneys to excrete this drug (9). That this indicates an essential qualitative difference between human nephritis and that induced in the rats is doubtful, for renal failure was not present in these rats while it has been observed in patients who failed to excrete the drug normally.

\section{CONCLUSIONS}

Sulfanilamide, given in therapeutic doses for long periods to rats with nephrotoxic nephritis, did not affect the course of the experimental disease.

Rats with nephrotoxic nephritis, but without renal failure, excreted sulfanilamide in the same amounts as did normal rats. Incidently, it was found that rats of the Whelan and Evans strains respond differently to the effect of nephrotoxic serum and diet.

\section{BIBLIOGRAPHY}

1. Marshall, E. K., Jr., Cutting, W. C., and Emerson, K., Jr., Toxicity of sulfanilamide. J. A. M. A., 1938, 110, 252.

2. Molitor, H., and Robinson, H., Some pharmacological and toxicological properties of sulfanilamide and benzylsulfanilamide. J. Pharmacol. and Exp. Therap., 1939, 65, 405.

3. Davis, H. A., Harris, L. C., Jr., and Schmeisser, H. C., Tissue changes following prolonged administration of sulfanilamide in rats. Arch. Path., 1938, 25, 750.

4. Marshall, E. K., Jr., Bacterial chemotherapy. Pharmacology of sulfanilamide. Phys. Rev., 1939, 19, 240. 
5. Farr, L. E., and Smadel, J. E., Influence of diet on course of nephrotoxic nephritis in Rats. Proc. Soc. Exp. Biol. and Med., 1937, 36, 472.

Smadel, J. E., and Farr, L. E., Effect of diet on pathological changes in rats with nephrotoxic nephritis. Am. J. Path., 1939, 15, 199.

6. McGregor, L., Finer histology of normal glomerulus. Am. J. Path., 1929, 5, 545.

7. Marshall, E. K., Jr., and Cutting, W. C., Absorption and excretion of sulfanilamide in mouse and rat. Bull. Johns Hopkins Hosp., 1938, 63, 328.

8. Marshall, E. K., Jr., Determination of sulfanilamide in blood and urine. J. Biol. Chem., 1937-38, 122, 263.

9. Marshall, E. K., Jr., Emerson, K., Jr., and Cutting, W. C., Para-aminobenzene-sulfonamide absorption and excretion: Method of determination in urine and blood. J. A. M. A., 1937, 108, 953.

10. Gross, P., Cooper, F. B., and Lewis, M., Urinary concretions caused by sulfapyridine. Proc. Soc. Exp. Biol. and Med., 1939, 40, 448.

11. Antopol, W., and Robinson, H., Urolithiasis and renal pathology after oral administration of 2(sulfanilylamino) pyridine (sulfapyridine). Ibid., $1939,40,428$. 